\title{
Cancer specific promoter CpG Islands hypermethylation of HOP homeobox (HOPX) gene and its potential tumor suppressive role in pancreatic carcinogenesis
}

Mina Waraya*, Keishi Yamashita, Hiroshi Katoh, Akira Ooki, Hiroshi Kawamata, Hiroshi Nishimiya, Kazunori Nakamura, Akira Ema and Masahiko Watanabe*

\begin{abstract}
Background: We have recently identified HOP hoemobox (HOPX) as a tumor suppressor gene candidate, characterized by tumor-specific promoter DNA hypermethylation in human cancers, and it can remarkably inhibit tumors' aggressive phenotypes. In this current study, we for the first time examined methylation level of HOPX and tested the functional relevance in pancreatic cancer (PC).

Methods: Clinical features of HOPX promoter hypermethylation was investigated in 89 PC tissues, and immunohistochemistry was added. We also examined its functional relevance in phenotype assays such as soft agar, proliferation, invasion, and cell cycle analysis.

Results: PC tissues had HOPX gene hypermethylation as compared to the corresponding normal pancreas tissues, and its uniqueness was robust to discriminate tumor from normal tissues ( $A \cup C=0.85, P<0.0001$ ). Unexpectedly, $\mathrm{HOPX}$ was increased in expression in tumor tissues, and immunohistochemistry revealed its predominant expression in the Langerhans islet cells, where HOPX was reduced in expression for PC cells with promoter hypermethylation. HOPX transfectants exhibited G1 arrest with subG1 accumulation, and inhibited tumor forming and invasive ability.
\end{abstract}

Conclusion: Defective expression of HOPX which is consistent with promoter DNA hypermethylation may explain aggressive phenotype of pancreatic cancer, and intense expression of HOPX in the Langerhans cells may in turn uniquely contribute to pancreatic carcinogenesis.

Keywords: HOP homeobox, Pancreatic cancer, Methylation

\section{Background}

Global hypomethylation is often accompanied by dense hypermethylation of the specific promoters in human cancers [1-3]. Promoter hypermethylation results in gene silencing, and such genes have proved to have potent tumor suppressive function and is rather rare $[1,4]$. We previously developed pharmacologic reversal of epigenetic silencing and uncovered a myriad of transcriptionally repressed genes in human cancers $[5,6]$. Using this

\footnotetext{
* Correspondence: komulu@hotmail.co.jp; gekaw@med.kitasato-u.ac.jp Department of Surgery, Kitasato University Hospital, 1-15-1 Kitasato, Minami-ku, Sagamihara, Kanagawa 252-0375, Japan
}

technique, we have identified several unknown tumor suppressor gene candidates, which included HOP homeobox (HOPX) $[7,8]$.

HOPX gene (GeneBank accession number NT 022853), also known as HOP, NECC1, LAGY or OB1, was initially identified as a gene essential for cardiac growth and development [9]. Three spliced transcript variants, HOPX- $\alpha,-\beta$, and $-\gamma$, encode the same protein, which contains a putative homeodomain motif that acts as an adapter protein to mediate transcription [10]. HOPX expression is ubiquitous in wide arrays of normal tissue, but not in malignant tissues including choriocarcinoma, lung, uterine endometrial, and gastrointestinal 
(GI) cancers $[7,8,11-15]$. The inactivation mechanism actually involves promoter methylation in esophageal, endometrial, and gastric cancer $[7,8,15]$. Also, enforced HOPX expression inhibited tumor growth and RNA interference knockdown of endogenous HOPX restored it $[7,8,15]$. These findings suggest that the HOPX gene acts as a tumor suppressor gene.

In this study, we for the first time studied methylation level of HOPX gene in PC and added the functional assay to answer the question whether HOPX plays an important role in pancreatic carcinogenesis.

\section{Methods}

\section{Cell lines and tissue samples}

The pancreatic cancer cell lines, PK-8, KLM-1, and NOR-P1 were kindly provided from the Cell Resource Centre for Biomedical Research Institute of Development, Aging and Cancer, Tohoku University (Sendai, Japan). Six other cell lines, PK-59, PK-45 H, PK-45P, MIA Paca2, PANC-1, or the esophageal squamous cell carcinoma (ESCC) cell line TE15 [16] and gastric cancer cell line KatoIII were purchased from RIKEN BioResource Centre (Ibaraki, Japan). All cell lines except MIA Paca2 were maintained in RPMI 1640 Medium (GIBCO, Carlsbad, CA) and MIA Paca2 was maintained in DMEM (GIBCO), containing 10\% fetal bovine serum.

Clinical tissue samples were categorized according to TNM classification, $7^{\text {th }}$ edition of the Union Internationale Contre Le Cancer (UICC) and the $6^{\text {th }}$ edition of the Japan Pancreas Society (JPS). The patients' characteristics were depicted in Additional file 1 Table S1. All tissue samples were collected at the Kitasato University Hospital, and informed consent was obtained. The present study was approved by the Ethics Committee of the Kitasato University.

\section{Bisulfite treatment of DNA and sequencing analysis}

Genomic DNA from homogenized bulky tissues and cell lines was extracted using QIAamp DNA Mini Kit (QIAGEN Sciences, Hilden). Bisulfite treatment was done by using an EpiTect bisulfite kit (QIAGEN) and the DNA was applied to polymerase chain reaction (PCR). PCR primer sequences were designed using DNA sequences converted by bisulfited treatment (Table 1). The PCR products were sequenced using a Big Dye ${ }^{\circledR}$ Terminator v3.1 Cycle Sequencing Kit (Applied Biosystems, Foster City, CA). For the clonsed sequence analysis, the PCR products were inserted into pCR4-TOPO vector using a TOPO TA cloning kit for sequencing (Invitrogen, Carlsbad, CA, USA), selected 15 clones for each sample and then sequenced.

\section{Quantitative-methylation-specific PCR (Q-MSP)}

TaqMan methylation specific PCR (Q-MSP) was carried out using iQ Supermix (Bio-Rad) in triplicate on the
iCycler $\mathrm{iQ}^{\mathrm{TM}}$ Real-Time PCR Detection system (BioRad). PCR conditions and the primer sequences are provided in Table 1. Serial dilutions of bisulfite modified DNA from KatoIII were used as positive control and TE15 as negative control, respectively. The methylation value was defined by a ratio of HOPX- $\beta$ divided by $\beta$ actin and then multiplied by 100 , according to the comparative cycle threshold $\left(\mathrm{C}_{\mathrm{T}}\right)$ method [17].

\section{RNA purification and reverse transcriptase-polymerase chain reaction}

Total RNA from homogenized bulky tissues and cell lines was extracted using RNeasy Mini Kit (QIAGEN), and reverse-transcribed with a SuperScript III Reverse Transcriptase kit (Invitrogen). Quantitative real time RT-PCR (Q-RT-PCR) for HOPX- $\beta$ or HOPX-core was performed using $\mathrm{iQ}^{\mathrm{TM}}$ SYBR Green Supermix (Bio-Rad) in triplicate on the $\mathrm{iCycler}_{\mathrm{iQ}}{ }^{\mathrm{TM}}$ Real-Time PCR Detection system (Bio-Rad), either (Table 1). Relative quantitative analysis adjusted for $\beta$-actin was performed according to the $C_{T}$ method [17]. Table 1 depicts sequences of primers/probes and PCR condition.

\section{Immunoprecipitation and Western blotting}

Whole cells lysates were obtained using RIPA buffer (Pierce, Rockford, IL) supplemented with $10 \mu \mathrm{L} / \mathrm{ml}$ Halt $^{\mathrm{TM}}$ Protease Inhibitor Cocktail Kit (Pierce) and Halt $^{\mathrm{TM}}$ Phosphatase Inhibitor Cocktail Kit (Pierce). Immunoprecipitation (IP) was performed using Dynabeads Protein G (Dynal Biotech, Oslo, Norway), $1 \mu \mathrm{g}$ of anti-HOPX mouse $\operatorname{IgG}_{1 \mathrm{~K}}$ monoclonal antibody (3D6, Sigma), and $400 \mu \mathrm{g}$ of each cell lysates. The anti-HOPX mouse $\operatorname{IgG}_{1 \mathrm{~K}}$ monoclonal antibody (3D6, dilution of 1:1000, Sigma), anti-HOPX rabbit IgG polyclonal antibody (FL-73, dilution of 1:200, Santa Cruz Biothecnology, Santa Cruz, CA, USA), anti-V5 mouse $\operatorname{IgG}_{2 \mathrm{a}}$ monoclonal antibody (dilution of 1:5000, Invitrogen), and anti- $\beta$-actin mouse $\operatorname{IgG}_{2 \mathrm{a}}$ monoclonal antibody (dilution of 1:10000, Sigma) were used for Western blotting (WB) or IP/WB.

\section{5-Aza-dC and TSA treatment}

Cells $\left(1 \times 10^{6}\right.$ cells/T-75 flask) were treated with 1 or $5 \mu \mathrm{M}$ of the demethylating agent 5 -aza-2/-deoxycytidine (5-Aza-dC) (Sigma-Aldrich) dissolved in 50\% acetic acid or mock-treatment with PBS including the same amount of acetic acid every 24 hrs for 4 days. When combined with the histone deacetylase inhibitor trichostatin A (TSA) (Sigma-Aldrich), $300 \mathrm{nM}$ TSA was added to the medium for the final 24 hrs.

\section{Immunohistochemistry}

Formalin fixed, paraffin-embedded histological sections (3 $\mu \mathrm{m}$ thick) were immunostained using the HOPX 
Table 1 PCR production and sequence of primers and fluorescent probe

\begin{tabular}{|c|c|c|c|c|}
\hline Method & Gene & Forward primer $\left(5^{\prime}>3^{\prime}\right)$ & Fluorescent $\left(5^{\prime} 3^{\prime}\right)$ & Reverse primer $\left(5^{\prime}>3^{\prime}\right)$ \\
\hline bisulfite sequencing $^{\dagger}$ & HOPX- $\beta$ & TAGTITTGTITGGAAGAGGGGCG & & AACCTCCCCTAAAAACAAACTTAAC \\
\hline Q-MSP* & HOPX- $\beta$ & TाTGGAGAGGGTTTAAAGCG & FAM-CGGAGATAGAAGGTCGTTTATCGGGGAGGTCG-TAMRA & AACAAACTTAACAAATCGCGAA \\
\hline Q-MSP* & $\beta$-actin & TGGTGATGGAGGAGGTTTAGTAAGT & FAM-ACCACCACCCAACACACAATAACAAACACA-TAMRA & AACCAATAAAACCTACTCCTCCCTTAA \\
\hline RT-PCR $\$$ & HOPX-a and $\gamma$ & CAAACCCAGGGCTTGCGCTT & & GCGGAGGAGCGAAACAGAGAT \\
\hline RT-PCR $\$$ /Q-RT-PCR & HOPX- $\beta$ & GGTCCCCCTITCGGGAGGAA & & GCGGAGGAGAGAAACAGAGAT \\
\hline RT-PCR $/ Q-R T-P C R$ & HOPX-core & CAGAGGACCAGGTGGAAATCC & & GCGGAGGAGAGAAACAGAGAT \\
\hline RT-PCR $/$ Q-RT-PCR & $\beta$-actin & GCTCGTCGTCGACAACGGCTC & & CAAACATGATCTGGGTCATCTTCT \\
\hline PCR for cloning ${ }^{\#}$ & HOPX & CACCATGTCGGCGGAGACCGCGAGCGG & & GTCTGTGACGGATCTGACACTCTG \\
\hline
\end{tabular}

Abbreviations: Tm, annealing temperature.

: Bisulfite sequencing PCR was done at $95^{\circ} \mathrm{C}$ for 3 min followed by 40 cycles at $95^{\circ} \mathrm{C}$ for $1 \mathrm{~min}, 72^{\circ} \mathrm{C}$ for $2 \mathrm{~min}$, and final extension at $72^{\circ} \mathrm{C}$ for $10 \mathrm{~min}$,in a $50 \mu \mathrm{\mu l}$ reaction volume containing $1 \mu \mathrm{\mu l}$ treated DNA, $5 \mu \mathrm{l} 10 \mathrm{X}$ PCR buffer, $0.2 \mu \mathrm{m}$ ol/ $/ \mathrm{MgCl} 2,0.2 \mu \mathrm{mol} / / \mathrm{l}$ each primer and $0.2 \mu \mathrm{l}$ Platinum ${ }^{\circledR}$ Taq DNA Polymerase.

†: Q-MSP was done at $95^{\circ} \mathrm{C}$ for $3 \mathrm{~min}$ followed by $45 \mathrm{cycles}$ at $95^{\circ} \mathrm{C}$ for $20 \mathrm{sec}, 60^{\circ} \mathrm{C}$ for $30 \mathrm{sec}$, and $72^{\circ} \mathrm{C}$ for $30 \mathrm{sec}$, in a $25 \mu \mathrm{l}$ reaction volume containing $100 \mathrm{ng}$ treated DNA, $300 \mathrm{nmol} / \mathrm{l}$ fluorescent probe, and $25 \mu \mathrm{l}$ $\mathrm{IQ}^{\mathrm{TM}}$ supermix.

§: RT-PCR was done at $95^{\circ} \mathrm{C}$ for $3 \mathrm{~min}$ followed by 30 cycles at $95^{\circ} \mathrm{C}$ for $1 \mathrm{~min}, 60^{\circ} \mathrm{C}$ for $1 \mathrm{~min}$, and final extension at $72^{\circ} \mathrm{C}$ for 1 min, and final extension at $72^{\circ} \mathrm{C}$ for 10 min, in a $50 \mu \mathrm{l}$ reaction volume containing $1 \mu l$ CDNA, $5 \mu \mathrm{l}$ 10x PCR buffer, $0.2 \mu \mathrm{mol} / \mathrm{l}$ dNTP mixture, $1.5 \mathrm{mmol} / \mathrm{l} \mathrm{MgCl}, 0.2 \mu \mathrm{m}$ ol/l each primer and $0.2 \mu \mathrm{l}$ Platinum ${ }^{\circledR}$ Taq DNA Polymerase.

: Q-RT-PCR was done at $95^{\circ} \mathrm{C}$ for $2 \mathrm{~min}$ followed by $40 \mathrm{cycle}$ at $95^{\circ} \mathrm{C}$ for $15 \mathrm{sec}, 60^{\circ} \mathrm{C}$ for $30 \mathrm{sec}$, and $72^{\circ} \mathrm{C}$ for $30 \mathrm{sec}$, in a $25 \mu$ reaction volume containing $100 \mathrm{ng}$ treated DNA, $300 \mathrm{nmol} / \mathrm{l}$ each primer, and $25 \mu$ iQTMPCR Mix.

\#: PCR was done at $94^{\circ} \mathrm{C}$ for $2 \mathrm{~min}$ followed by $35 \mathrm{cycles}$ at $94^{\circ} \mathrm{C}$ for $15 \mathrm{sec}, 64.8^{\circ} \mathrm{C}$ for $15 \mathrm{sec}, 68^{\circ} \mathrm{C}$ for $30 \mathrm{sec}$, and final extension at $68^{\circ} \mathrm{C}$ for $7 \mathrm{~min}$, in a $50 \mu \mathrm{l}$ reaction volume containing $1 \mu \mathrm{l} \mathrm{CDNA}, 5 \mu \mathrm{l} 10 \times$ $\mathrm{Pf} \times 50^{\mathrm{TM}} \mathrm{PCR}$ Mix, $0.3 \mu \mathrm{mol} / \mathrm{I} \mathrm{dNTP}$ mixture, $0.3 \mu \mathrm{mol} / \mathrm{l}$ each primer and $1 \mu \mathrm{l} \mathrm{Pf} \times 50^{\mathrm{TM}}$ DNA Polymerase. 


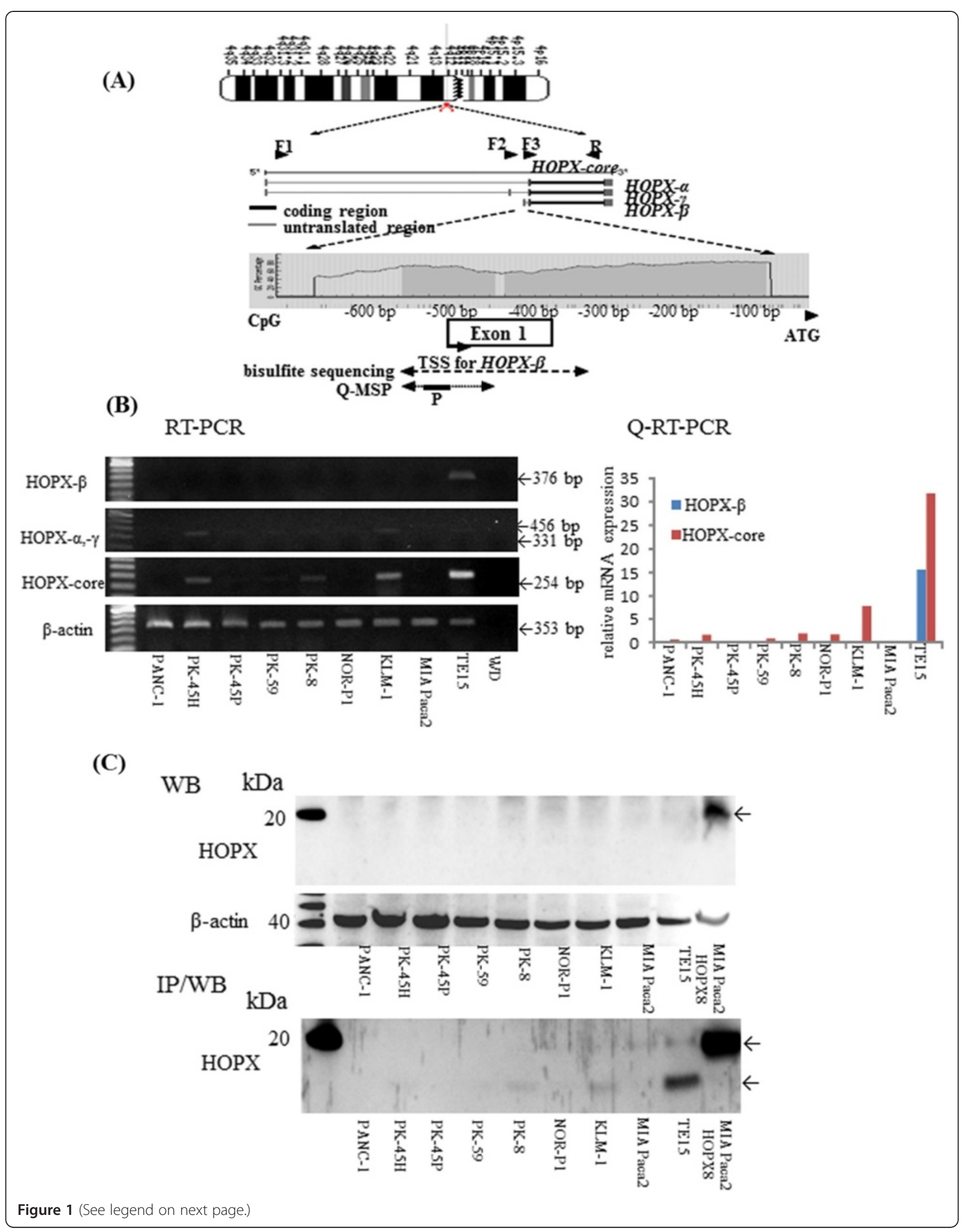


(See figure on previous page.)

Figure 1 Analysis of HOPX- $\beta$ methylation and expression in pancreatic cancer cell lines-1. (A) Schematic diagram of the 3 spliced transcript variants and common transcript core in HOPX (middle panel) and of CpG islands (gray area) in the 5/-flanking region of HOPX gene (bottom panel). Vertical bars indicate the dinucleotides CPG. Arrows indicate the sequences for bisulfite sequencing analysis or Q-MSP, respectively. F1, F2 and F3 represent forward primers for HOPX-a (331 bp) and HOPX- $\gamma$ (456 bp), HOPX- $\beta$ (376 bp), and HOPX-core (254 bp) in RT-PCR or Q-RT-PCR; R, common reverse primer; P, probe for Q-MSP; TSS, transcription start site; ATG, translation start codon. (B) Expression level of HOPX in PC cell lines was examined by RT-PCR (left panel) and Q-RT-PCR (HOPX- $\beta$ and core/ $\beta$-actin x 100, (right panel). (C) Expression level of HOPX in PC cell lines was examined by WB (top panel) and IP/WB (bottom panel). Transfectants we performed had the V5 epitope and polyhistidine region in the C-terminal peptide, and so, added approximately 5 kDa to original protein.

antibody (3D6, dilution of 1:200). And immune complexes were detected using the 3,3/-diamino-benzidine tetrahydrochloride (DAB) substrate, as a chromogen for 30 seconds or 2 minutes.

\section{Plasmid and transfection}

A full length cDNA of HOPX was previously isolated and subcloned into pcDNA ${ }^{\mathrm{TM}_{3}}$.1D/V5-His-TOPO vector $\left(\mathrm{pcDNA}^{\mathrm{TM}} 3.1-\mathrm{HOPX}\right)$ [8]. The vector with selfligation was used as a mock control. Plasmid vectors were transfected into 2 pancreatic cancer cell lines (MIA Paca2 and PANC-1) using Lipofectamine 2000 reagent (Invitrogen). Stable clones with HOPX or mock were established by G418 (GIBCO) selection (MIA Paca2, $800 \mu \mathrm{g} / \mathrm{ml}$; PANC-1, $1200 \mu \mathrm{g} / \mathrm{ml})$.

\section{Proliferation assay}

Cell proliferation and viability $\left(2 \times 10^{3}\right.$ cells/well $)$ were measured using the Premix WST-1 Cell Proliferation Assay System (Takara Bio, CO., Tokyo, Japan) in 96-well plates. Experiments were performed in triplicate.

\section{Invasion assay}

Cells were seeded at density of $1 \times 10^{6}$ cells/well in the 24-well BD BioCoat Matrigel Invasion Chamber (BD Biosciences Discovery Labware, Bedford, MA) filled with $500 \mu \mathrm{l}$ DMEM (GIBCO). As a chemoattractant, 10\% FBS in $750 \mu \mathrm{l}$ DMEM (GIBCO) was used for the assay. After incubation for $22 \mathrm{hrs}$, the membrane of the upper chamber was fixed and stained by Diff-Quick reagent (Sysmex, Kobe, Japan). Invaded cells were counted in for randomly selected sites per membrane.

\section{Anchorage-independent colony formation assay}

Anchorage-independent cell growth was analyzed by plating $0.36 \%$ top agarose (Bacto $^{\mathrm{TM}}$ Ager, Becton Dickison and Company, Franklin Lakes, NL) containing $1 \times 10^{5}$ cells on a surface of $0.72 \%$ bottom agarose in 6 well plates. Two independent experiments were performed and each experiment was done in triplicate.

\section{Cell cycle assay}

Cells $\left(1 \times 10^{6}\right.$ cells $\left./ \mathrm{ml}\right)$ were fixed in $75 \%$ ethanol, $5 \times 10^{5}$ cells stained with propidium iodide (Guava cell cycle reagent, Guava Technologies, Hayward, CA) and the cell cycle assay was carried out using the Guava PCA System. The experiment was performed in triplicate and analyzed using CytoSoft 2.1.5 software (Guava Technologies).

\section{Statistical analysis}

Fisher's exact test, the chi-square test, Mann-Whitney's $\mathrm{U}$ test or Kruskal-Wallis rank test used for categorical variables, and Student's t-test was used for continuous variables. Clinicopathological characteristics and follow up data were analyzed in association with 5 year disease specific survival (DSS). The follow up time was calculated from the date of surgery to death. DSS was calculated by Kaplan-Meier method, and survival differences were assessed in the log-rank test. Variables suggested to be prognostic factors on univariable analysis $(\mathrm{P}<0.05)$ were subjected to multivariable analysis using a Cox proportional-hazards regression model. Data is expressed as mean \pm standard deviation (SD), and P-value $<0.05$ was considered to indicate statistical significance. All statistical analyses were conducted with SAS software package (SAS Institute, Cary, NC).

\section{Results}

Structure of HOPX promoter region

Genomic structure of HOPX gene is shown in Figure 1A. HOPX has 3 unique transcript variants with 2 discrete promote regions, and all of the 3 transcripts have the same open reading frame. Among the 3 variants, only HOPX- $\beta$ harbours promoter $\mathrm{CpG}$ islands (promoter $\mathrm{B}$ ) encompassed by the first exon and intron [8].

\section{Expression level of HOPX transcripts (core and each transcript- $\alpha, \beta$, and $\gamma$ ) and protein in PC cell lines}

We first examined expression of HOPX core transcripts, in which PCR primers were shared for all the 3 transcripts (Figure 1A). Among the 8 PC cell lines tested, only KLM-1, PK-8, and PK-45 H cells express slight expression of HOPX core transcript, where HOPX core transcript is consistent with $\mathrm{HOPX}-\alpha /-\gamma$ transcripts. On the other hand, HOPX- $\beta$ was not detected at mRNA level in any $8 \mathrm{PC}$ cell lines (Figure $1 \mathrm{~B}$ ). WB analysis also revealed that HOPX protein was hardly detected in any 


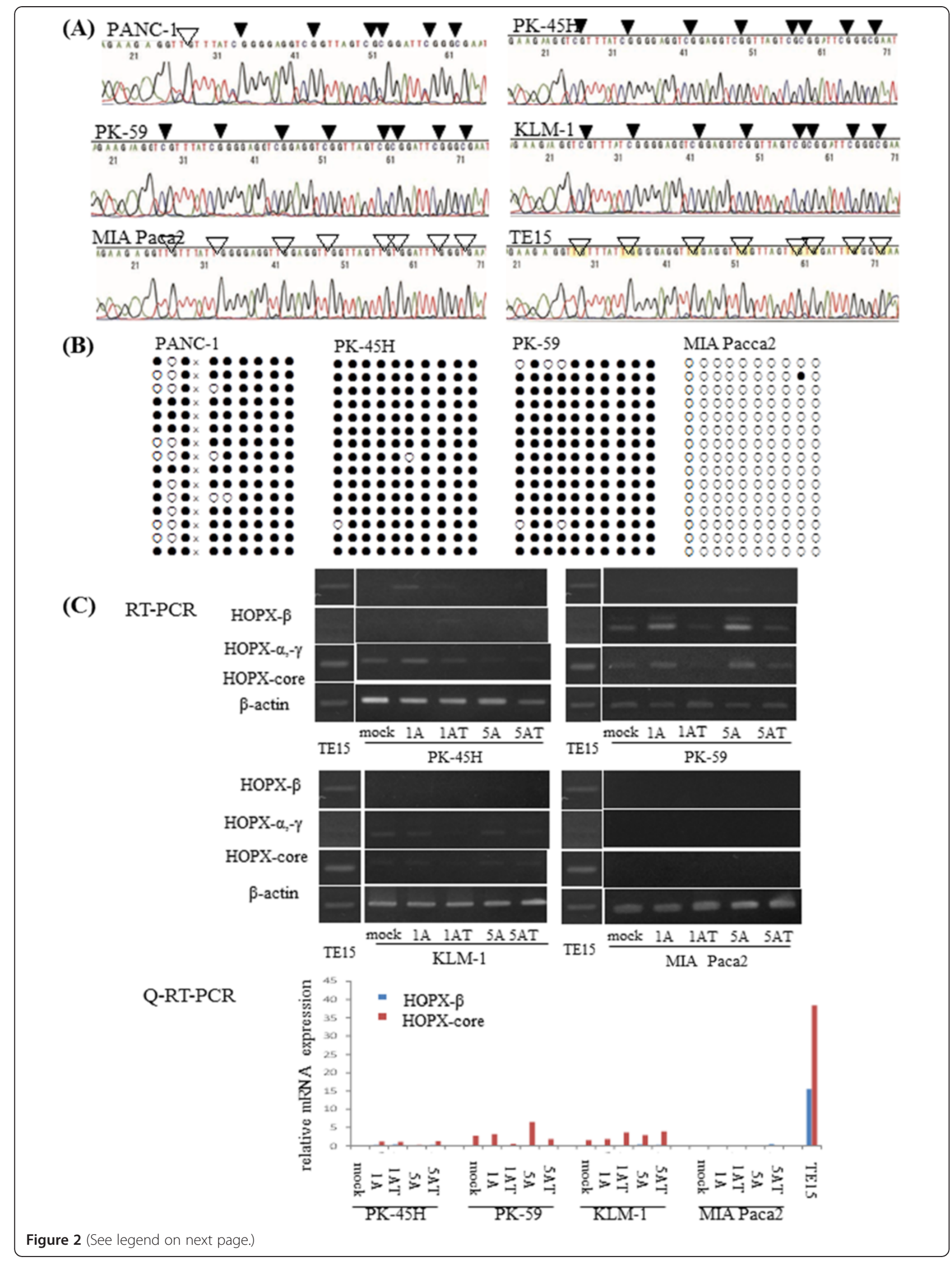


PC cell lines. We therefore added experiments of IP/WB (Figure 1C), which could detect very weak but consistent expression of HOPX protein in KLM-1, PK-8, and PK$45 \mathrm{H}$ at $10 \mathrm{kDa}[7,9,14]$. As HOPX transfectants and positive control TE15 showed considerable expression (Figure 1C), we concluded that HOPX expression showed very little, if any, in PC cells.

\section{Characteristics of promoter B methylation in PC cell lines}

We initially examined the HOPX- $\beta$ promoter methylation in all the 8 PC cell lines by bisulfite treatment followed by direct sequencing, and promoter B of HOPX gene was proved to be completely methylated in cytosine residues of $\mathrm{CpG}$ islands in $7 \mathrm{PC}$ cells except PANC-1 and MIA Paca2 (Figure 2A, B).

In order to demonstrate whether HOPX silencing of PC cells is due to epigenetic abnormalities, demethylating agents such as 5-Aza-dC and/or trichostatin A were added to PC cells, and reactivation of HOPX transcripts was evaluated by RT-PCR and Q-RT-PCR (Figure 2C). Differently from other GI cancers, reactivation was recognized in small portions of PC cells to the small extent (Figure 2C). Reactivation by the most optimal demethylating conditions was only found in PK-45 $\mathrm{H}$ and PK-59, suggesting that reduction of HOPX gene could be partially explained by epigenetic alterations of HOPX promoter B. HOPX absent expression in MIA Paca2 was also confirmed even after epigenetic reversion. We could have therefore postulated homozygous deletion to explain this absent expression. However, DNA could be amplified for the promoter regions of HOPX- $\beta$, and actual cloned sequence largely showed unmethylation in MIA Paca2 (Figure 2B). Other cancer cell lines also showed very little expression of $\mathrm{HOPX}-\beta$, so constitutive transcription signal to activate HOPX- $\beta$ expression was defective in PC cell lines. However, this result does not represent meaningless significance of HOPX methylation, and we continued methylation analysis in primary PC tissues.

\section{Expression of HOPX transcripts and protein in PC tissues and the corresponding normal pancreas tissues}

We first examined the expression status of HOPX transcripts for both the primary tumors and the corresponding pancreas tissues in the 5 consecutive advanced PC patients by both semi-quantitative RT-PCR and Q-RT-PCR. As a result, HOPX- $\beta$ transcripts were rather robustly over-expressed in the primary $\mathrm{PC}$ tissues as compared to the corresponding normal tissues (Figure 3A). WB also showed HOPX protein overexpression in tumor tissues as compared to in the corresponding normal tissues (Figure 3B).

In order to confirm predominant localization of HOPX protein in primary $\mathrm{PC}$, we then performed immunohistochemistry (Figure 3C, D). Surprisingly, HOPX was strongly immunostained almost exclusively for pancreatic islet cells by short term exposure (30 seconds) of DAB. Neither cancer cells nor normal pancreatic components such as acinar and ductal cells showed staining of HOPX (Figure 3D). On the other hand, islet cells in normal pancreas also showed considerable immunostaining of HOPX (Figure 3D). These findings suggested that predominant expression of HOPX transcripts and protein in primary $\mathrm{PC}$ represents those of islet cells.

Instead of intense immunostaining of pancreas islet cells, pancreatic duct and a portion of acinar cells were also immunostained by intermediate exposure (2 minutes) of DAB (Figure 4A). The cellular localization of HOPX existed mainly in cytoplasm. Under such conditions, we investigated the IHC staining of HOPX for 11 cases with high methylation value and 9 cases with low methylation value, respectively. In high methylation value tissues, absent expression of HOPX was confirmed despite frequent inclusion of heterogeneity. However, 9 samples with low methylation value exhibited relatively strong HOPX expression, while only one sample showed negative expression (Figure 4A). These results indicated that expression of HOPX protein was associated with promoter hypermethylation.

Using the same primers and probes in gastric cancer study [8], we examined both 89 primary PC tissues and 84 corresponding non tumor tissues by Q-MSP analysis (Figure 4B). The most optimal cut-off value was calculated for 1.5 from a receiver-operator characteristic (ROC) analysis in order to maximize both sensitivity and specificity of PC detection (Figure 4C), where sensitivity was $83.2 \%$, and specificity was $76.2 \%$.

The overall methylation value detected in primary PC tissue $(14.50 \pm 16.53)$ was significantly higher than that in the non tumoral tissues $(3.64 \pm 12.02)(\mathrm{P}<0.0001)$ (Figure $4 \mathrm{~B})$. In addition, the methylation values within primary $\mathrm{PC}$ tissues were significantly higher than those within non tumor 


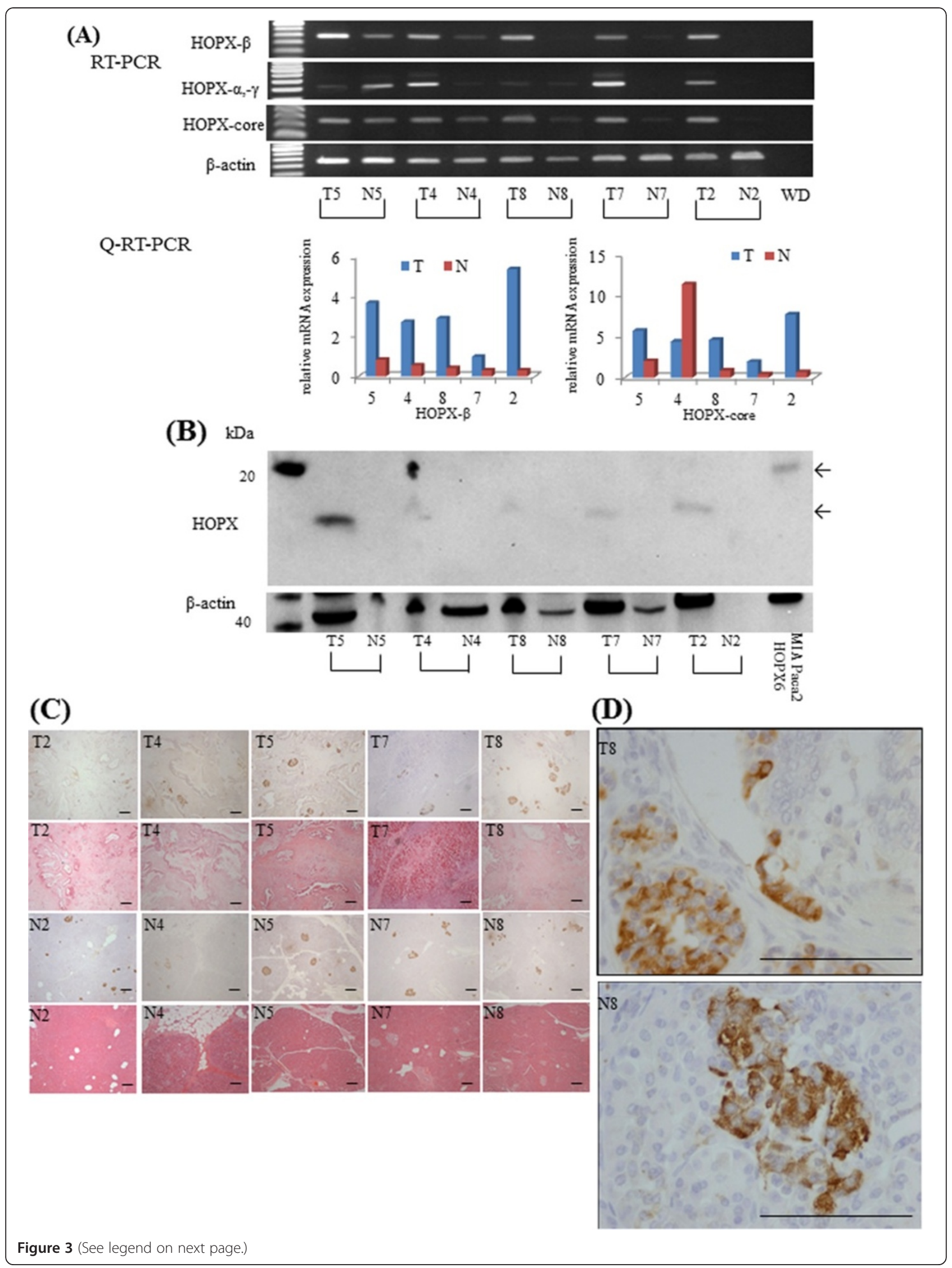


(See figure on previous page.)

Figure 3 HOPX expression status in PC. (A) Expression level of HOPX in PC was tested in RT-PCR (top panel) and Q-RT-PCR (bottom panel). T, primary tumor; N, corresponding pancreatic tissue. (B) Expression level of HOPX in PC was examined by western blotting.

(C) Immunohistochemical staining for HOPX in primary tumor (top panel) and normal tissue (bottom panel), with hematoxylin eosin staining (original magnification, X40). These immunohistochemical stainings were performed by short term exposure of DAB. (D) In this condition, islet cells only stained (original magnification, X400). scale Bars, $100 \mu \mathrm{m}$.

tissues in individual patients, whereas methylation values did not significantly differ in each stage (Figure 4D).

We further investigated whether the HOPX- $\beta$ methylation value was able to predict patient's outcomes. Logrank plot analysis [18] showed that any cut-off value could not represent prognostic stratification in PC (Figure 4E). We preliminarily analyzed the correlation between HOPX- $\beta$ hypermethylation and the clinicopathological parameters, but none of any clinicopathological variables was associated with methylation status of HOPX- $\beta$ (Additional file 2 Table S2).

\section{HOPX stable transfectants caused suppression of aggressive PC cell phenotypes}

Two cell lines of pancreatic adenocarcinoma such as PANC-1 and MIA Paca2 cells were transfected with

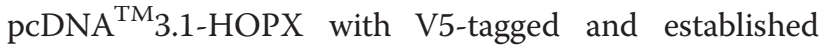
stable HOPX-expressing cell lines. In the HOPX stable cell lines, exogenous mRNA expression level in cells with the most abundant expression was comparable to physiological expression level in human PC tissues. HOPX protein was confirmed by 3D6 antibody and antiV5 antibody. Exogenously expressed tagged HOPX was detected as approximately $15 \mathrm{kDa}$ which is consistent with mRNA levels (Figure 5A).

HOPX transfectants showed both less viability by WST assay (Figure 5B) and remarkable reduction of colonies in soft agar (Figure 5C) as compared with mock cells. Moreover, we found considerable suppression of invasion activity in HOPX-expressing cells by Matrigel invasion assay (Figure 5E). Cell cycle analysis further revealed that HOPX increased fractions of both subG1 fraction and G0/G1, accompanied by decreased fraction of both $\mathrm{S}$ and G2/M, indicating that both $\mathrm{G} 1$ arrest and apoptotic sensitivity may be at least partially involved in tumor suppressive traits of HOPX-expressing cell (Figure 5D and Additional file 3 Table S3).

\section{Discussion}

We have recently identified HOPX as genes specifically methylated in human cancers $[7,8]$ after developing algorithm utilizing pharmacological unmasking microarray (PUM) [5,6]. Among the identified candidates of TSGs, HOPX is of particular interest in terms of methylation and functional involvement in tumor aggressiveness. Other groups also recapitulated the similar finding that
HOPX promoter DNA is hypermethylated specifically in endometrial cancer [15]. In this present study, we for the first time added pancreatic cancer to the list of organs in which HOPX is involved in carcinogenesis.

HOPX harbors 2 discrete promoter regions, promoter $\mathrm{A}$ and promoter B. Promoter B has CpG islands, while promoter A does not have them, and cancer-specific hypermethylation is recognized in the promoter B in primary PC tissues as well as other GI cancers $[7,8]$. Such independent regulation of the discrete promoter regions was reported in other critical methylation genes such as RASSF1 [19], and possession of the complex promoter regions may indicate their functional importance in biological relevance. On the other hand, epigenetic reactivation of HOPX gene expression was much less than expected in PC cell lines as compared to other GI cancer cell lines. Allowing for actual expression in primary cancer tissues, constitutive HOPX expression signal was derived from carcinoma-stroma interaction in primary PC cells.

Pancreatic cancer is a ductal carcinoma, however it is controversial which normal components (ductal cells, acinar cells, or islet cells) of the pancreatic tissues are precursor cells for PC [20,21]. Pour et al. proved that transplantation of islets into the submandibular gland of Syrian golden hamsters followed by treating with nitrosamine N-nitrosobis-(2-oxopropyl)amin (BOP), a carcinogen for $\mathrm{PC}$ led to the development of ductal pancreatic adenocarcinoma in this site, while PC did not occurred after transplanting ductal and acinar cells into this gland [22]. Schmied et al. has also insisted that islet cells contribute to pancreatic carcinogenesis in an animal model and disease exploration [23,24]. In mice with hamster islets implanted in the splenic lobe of the mouse pancreases, pancreatic ductal adenocarcinomas developed in the implanted animals, but not in control mice, after BOP treatment [25]. These findings strongly supported the hypothesis that PC is generated from islet cell origin. In this current study, we for the first time revealed that islet cells expressed abundant HOPX protein in primary PC tissues as well as the normal pancreas. It is intriguing hypothesis that cancer cell with low expression of HOPX is derived from islet cells which constitutively express abundant HOPX, and that promoter DNA hypermethylation is causative for gene silencing.

Clinical findings also supported hypothesis that the islet cell is alternatively involved in PC carcinogenesis 
(A) 1. non tumour tissue

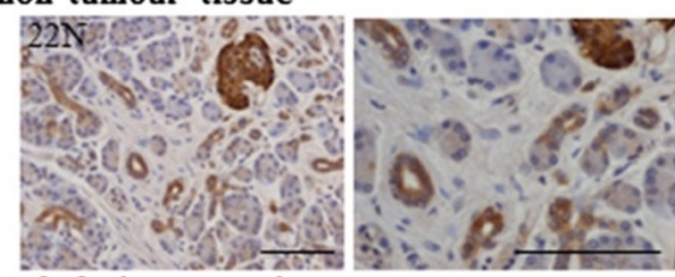

2. methylation negative case

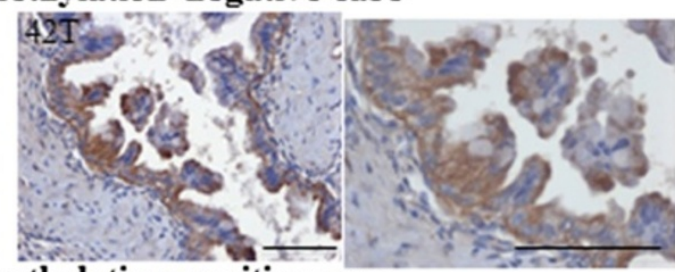

3. methylation positive case

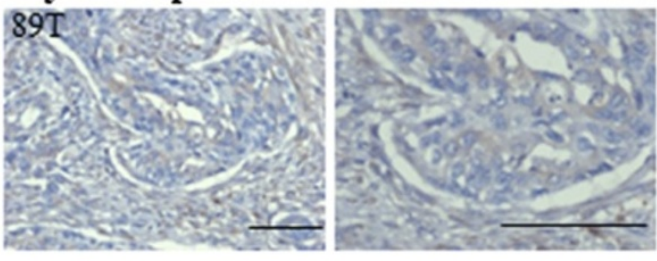

(C)

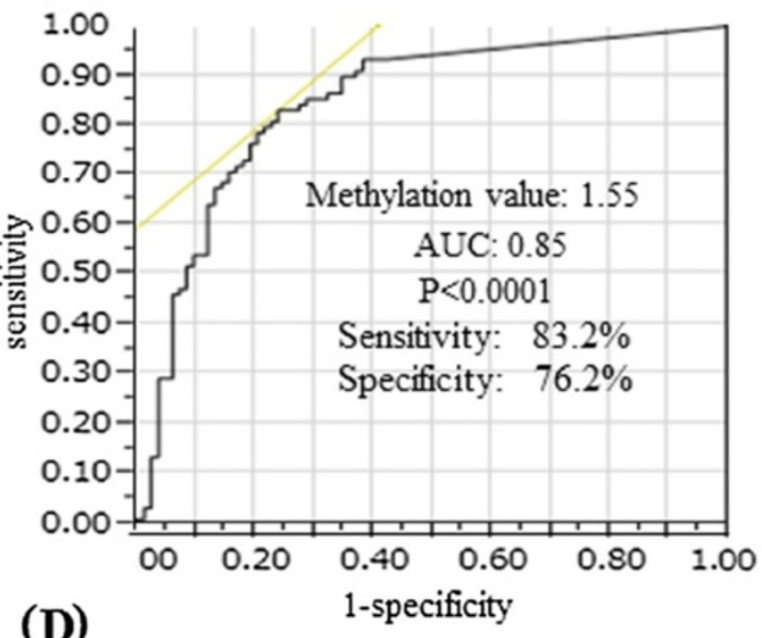

(D)
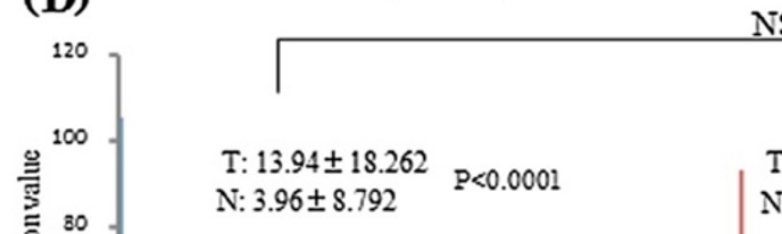

$\mathrm{T}: 16.32 \pm 14.972 \quad \mathrm{P}=0.01$ N: $5.17 \pm 19.272$ NS
(B)

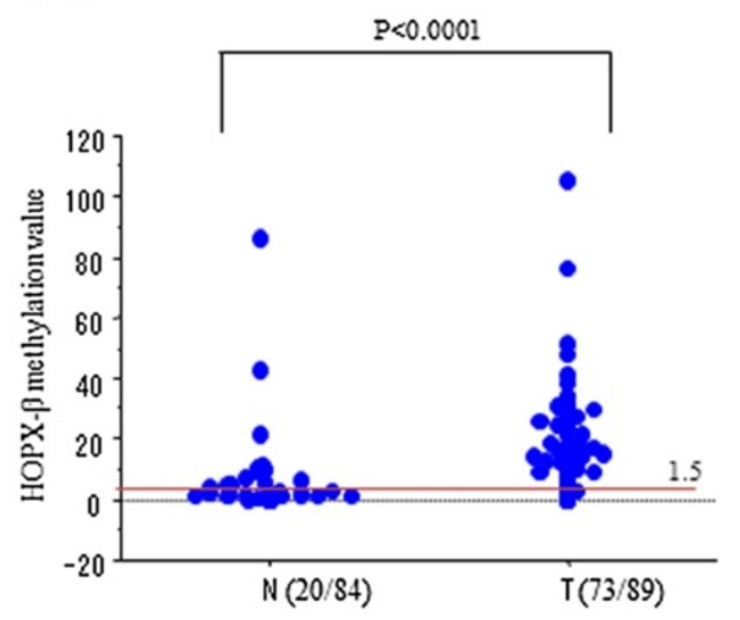

(E)

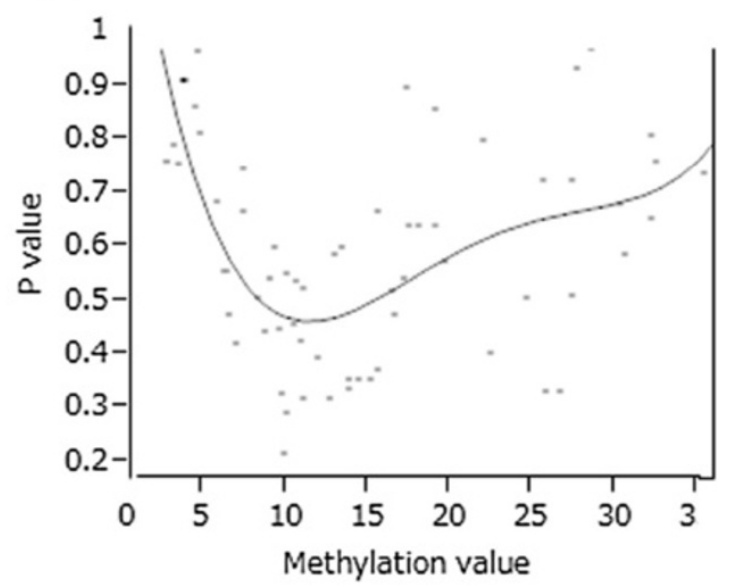


(See figure on previous page.)

Figure $\mathbf{4}$ Immunohistochemistry and Quantitative methylation analysis in $\mathbf{8 9}$ samples. (A) Representative immunohistochemical staining for HOPX in normal tissues and primary tumor with or without HOPX- $\beta$ hypermethylation (original magnification, left X200, right X400). scale Bars, $100 \mu \mathrm{m}$. (B) Frequency of HOPX- $\beta$ hypermethylation by Q-MSP. Dashed line indicates the optimal cut-off value (1.5). (C) ROC curve of HOPX- $\beta$ methylation for detection of PC. Area under the curve (AUC) represents the accuracy in discriminating normal from tumor in term of sensitivity and specificity $(P<0.0001)$. (D) Methylation value of HOPX- $\beta$ in JPS stage III, IVa and IVb. Data are expressed as mean \pm SD. (E) Identification of an optimal cut-off value for the prognosis using the log rank prognostic analysis.

[23], in which remarkable alteration of quality of islet cells was observed in primary PC tissues. Ten out of the 14 cancer specimens showed a significant loss of beta cells $(\mathrm{P}<0.005)$ and eight of them also showed a significant increase of alpha cells $(\mathrm{P}<0.005)$, all of them from hyperglycemic patients. Most affected islets were found within zone 1 (intratumoral) and zone 2 (peritumoral), to a lesser extent in zone 3 (acini close to tumor) and none in zone 4 (acini remote from tumor). The incidence of $72 \%$ with alteration of islets in their material correlates with the frequency of abnormal glucose levels in human pancreatic cancer patients. In our study, HOPX is remarkably increased in primary PC tissues, and it was predominantly expressed in the islet cells. These findings suggested that alteration of HOPX expression in the islet cells may explain the link of PC to diabetes mellitus, and this mechanistic possibility should be paid attention in the next future, as oncogenic role of islet cells remains elusive during $\mathrm{PC}$ carcinogenesis.

HOPX actually suppressed tumor aggressiveness of PC cells (PANC-1 and MIA Paca2). WST assay showed that HOPX suppressed cell viability putatively representing cell proliferation ability. In cell cycle analysis, HOPX increased subG1 and G0/G1 phases, representing apoptotic induction and inhibition of DNA synthesis, suggesting that cell cycle abnormalities may be linked to cell viability. More importantly, HOPX could inhibit tumor-forming ability in soft agar, which is supposed to represent metastatic trait of tumor cells [26]. Interestingly, HOPX has been demonstrated to suppress tumorigenesis in soft agar in ESCC and gastric cancer as well as pancreatic cancer, hence anchorage independent growth suppression is the common feature of HOPX expression in human cancers. Finally, HOPX also affects Matrigel invasion less than other phenotypes in PC. These findings may directly show gene silencing of HOPX involved in PC aggressiveness.

Such tumor suppressive effects as shown in Figure 5 might include artifact effect, because expression level of HOPX protein in transfectants may not correspond to the physiological level of the originated normal cell, if precursor cells of the PC were ductal or acinar cells. On the other hand, HOPX expression level of the islet cells reached similar level of the transfectants in our current study. More importantly, the level of expression in the transfectants of the current study was comparable with those of normal mucosa of other tissues such as gastric [8] and colorectal mucosa [27]. As compared to such common solid tumors, PC exhibited uniquely dismal prognosis, which is consistent with low expression of HOPX in PC. As constitutive expression of HOPX in human cancer cell lines including PC cell lines was infrequently found, RNA knockdown experiments was impossible to verify the endogenous role of HOPX in human pancreatic cancer cells, however we previously investigated RNA knockdown effects of HOPX by using esophageal cancer cells, TE15 that is a rare control cell which constitutively expressed HOPX $[7,8]$, and tumor suppressive role was confirmed. DNA hypermethylation of HOPX with gene silencing is therefore likely to affect PC phenotypes as in other cancers. On the other hand, there were some limitations of the conclusions that can be made based on our functional assay. In MIA Paca2 cells, HOPX was unlikely to be inactivated by methylation, and transfected HOPX protein of PANC-1 cells was expressed relatively weakly. Hence, our conclusion on tumor suppressive role of HOPX on PC was based largely on epigenetic characteristics in primary $\mathrm{PC}$, and results of PC cell lines remained supplementary. We would like to know more specific and definitive conclusions as to these concerns in the near future.

HOPX affects gene transcription through recruitment of HAT and/or HDAC activity for specific transcriptional factors [28-30]. Yeast two hybrid identified enhance of polycomb-1 (Epc-1), a critical component of NuA4 HAT complex, as a binding partner of HOPX, and augments transcription of heart differentiation genes. Interestingly, Epc1 was demonstrated to be associated with EZH2 which is required for cellular proliferation, E2F6-PcG complex (E2F6-EPC1) that interacts with EZH2 and may regulate genes required for cell cycle progression [31,32]. Thus, HOPX may therefore affect critical process of chromatin conformation change to affect expression of onco-molecules.

Collectively, we found that HOPX methylation is a very frequent and cancer specific event in PC development. We further elucidated that HOPX is a putative tumor suppressor gene critical for tumor aggressiveness in PC. We are also interested in alternate aspects of HOPX in terms of a role in islet cells. We must confirm 


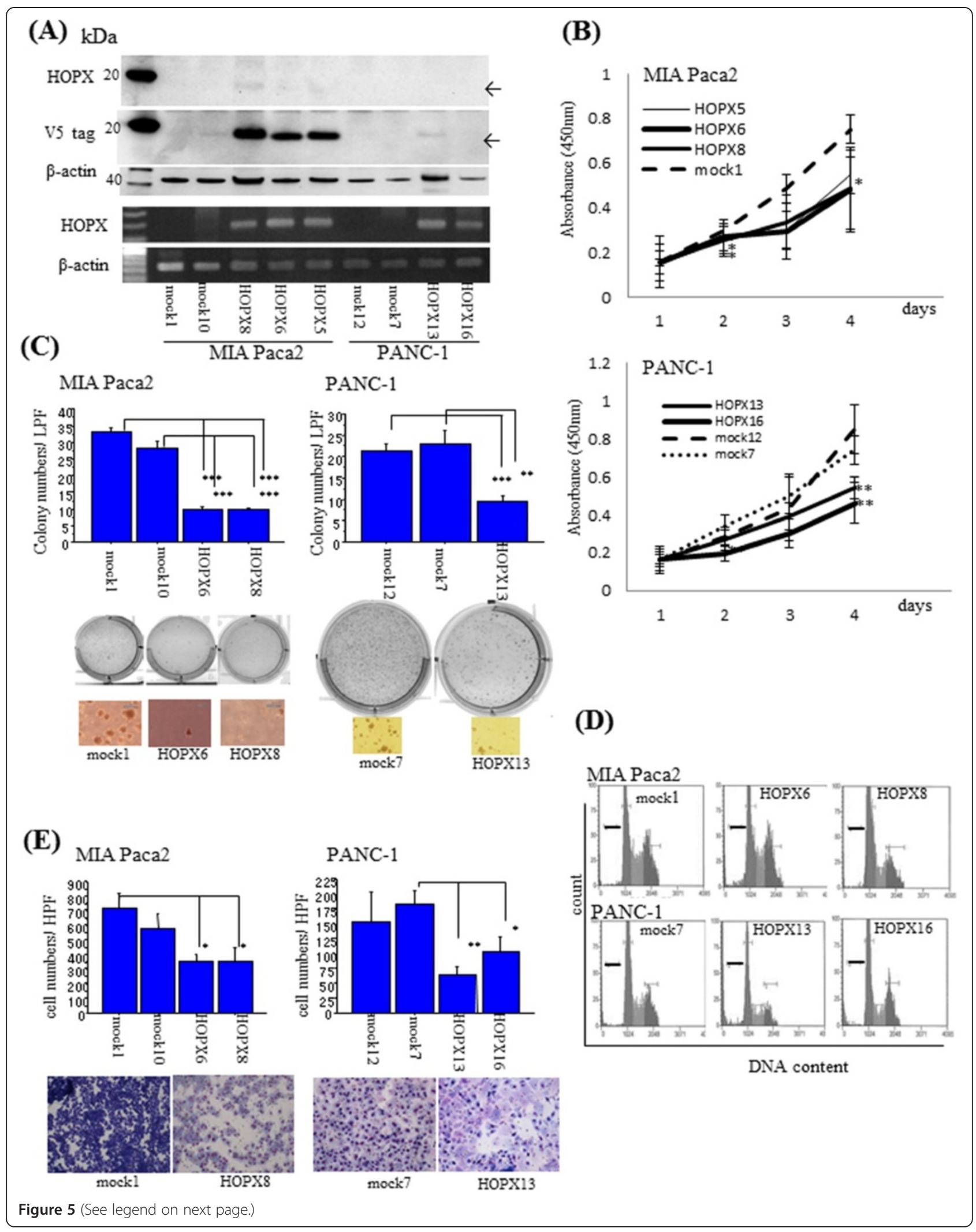


(See figure on previous page.)

Figure 5 Functional analysis of HOPX in PC cells. (A) HOPX expression level in HOPX expressing stable cell lines was determined by mRNA expression (lower panel) and protein expression (upper panel). HOPX protein was detected by WB with HOPX antibody (3D6) and the flag V5 antibody. $\beta$-actin was shown as a loading control. (B) Proliferation assay was performed for 5 days. Data are shown as absorbance at $450 \mathrm{~nm}$. error bars, SD. (C) Anchorage-independent colony formation assay was performed. After 3 weeks of cell culture, colonies were counted and photographed at 40x magnification under a microscope. Colonies were also visualized by ethidium bromide staining. error bars, SD. (D) Image of cell cycle assay. Thick black bars, subG1 phase. (E) Matrigel invasion assay. After fixation and staining, invading cells were photographed and counted at 100x magnification. error bars, SD.

more detailed mechanism involved in remarkable phenotype alteration by HOPX abnormalities in PC in future study.

\section{Conclusions}

Defective expression of HOPX which is consistent with CpG islands promoter DNA hypermethylation may explain aggressive phenotype of pancreatic cancer, and intense expression of HOPX in the Langerhans islet cells may in turn uniquely contribute to pancreatic carcinogenesis.

\section{Additional files}

Additional file 1: Table S1. Characteristics and prognostic analysis in 89 patients with pancreatic cancer.

Additional file 2: Table S2. Correlation analysis between HOPX- $\beta$ methylation status andclinicopathological variables $(n=89)$.

Additional file 3: Table S3. Distribution of cell cycle phase.

\section{Abbreviations \\ HOPX: Homeodomain-only protein; PC: Pancreatic cancer; Q-MSP: TaqMan methylation specific polymerase chain reaction; Q-RT-PCR: Quantitative reverse transcriptase-polymerase chain reaction; UICC: The union internationale contre le cancer; JPS: Japan pancreas society; ROC curve: Receiver-operator characteristic curve; SD: Standard deviation; DSS: Disease specific survival.}

\section{Competing interests}

There is no conflict of interest that could be perceived as prejudicing the impartiality of the research reported.

\section{Authors' contributions}

MW conceived of the study, performed the study, drafted the manuscript and participated in coordination. $\mathrm{KY}$ participated in coordination and assisted in editing of manuscript. $\mathrm{HK}, \mathrm{AO}, \mathrm{HK}, \mathrm{HN}, \mathrm{KN}$, and $\mathrm{AE}$ helped in the collection and analysis of clinical data. MW participated in coordination. All authors read and approved the final manuscript.

\section{Acknowledgements}

This work was supported in part by the Grant-in-Aid for Cancer Research from the Ministry of Health, Labor and Welfare of Japan and by the Japanese Foundation for Multidisciplinary Treatment of Cancer. The funding agencies had no role in the design of the study, data collection, or analysis; in the interpretation of the results; in the preparation of the manuscript; or in the decision to submit the manuscript for publication.

Received: 19 November 2011 Accepted: 31 August 2012

Published: 7 September 2012

\section{References}

1. Jones PA, Baylin SB: The epigenomics of cancer. Cell 2007, 128(4):683-692

2. Bird AP: $\mathrm{CpG}$-rich islands and the function of DNA methylation. Nature 1986, 321(6067):209-213
3. Goelz SE, Vogelstein B, Hamilton SR, Feinberg AP: Hypomethylation of DNA from benign and malignant human colon neoplasms. Science 1985, 228(4696):187-190.

4. Herman JG, Baylin SB: Gene silencing in cancer in association with promoter hypermethylation. N Engl J Med 2003, 349(21):2042-2054

5. Yamashita K, Upadhyay S, Osada M, Hoque MO, Xiao Y, Mori M, Sato F, Meltzer SJ, Sidransky D: Pharmacologic unmasking of epigenetically silenced tumor suppressor genes in esophageal squamous cell carcinoma. Cancer Cell 2002, 2(6):485-495.

6. Kim MS, Yamashita K, Baek JH, Park HL, Carvalho AL, Osada M, Hoque MO, Upadhyay S, Mori M, Moon C, et al: N-methyl-D-aspartate receptor type $2 B$ is epigenetically inactivated and exhibits tumor-suppressive activity in human esophageal cancer. Cancer Res 2006, 66(7):3409-3418.

7. Yamashita K, Kim MS, Park HL, Tokumaru Y, Osada M, Inoue H, Mori M, Sidransky D: HOP/OB1/NECC1 promoter DNA is frequently hypermethylated and involved in tumorigenic ability in esophageal squamous cell carcinoma. Mol Cancer Res 2008, 6(1):31-41.

8. Ooki A, Yamashita K, Kikuchi S, Sakuramoto S, Katada N, Kokubo K, Kobayashi H, Kim MS, Sidransky D, Watanabe M: Potential utility of HOP homeobox gene promoter methylation as a marker of tumor aggressiveness in gastric cancer. Oncogene 2010, 29(22):3263-3275.

9. Chen F, Kook H, Milewski R, Gitler AD, Lu MM, Li J, Nazarian R, Schnepp R, Jen $K$, Biben $C$, et al: Hop is an unusual homeobox gene that modulates cardiac development. Cell 2002, 110(6):713-723.

10. Kook H, Yung WW, Simpson RJ, Kee HJ, Shin S, Lowry JA, Loughlin FE, Yin Z, Epstein JA, Mackay JP: Analysis of the structure and function of the transcriptional coregulator HOP. Biochemistry 2006, 45(35):10584-10590

11. Asanoma K, Matsuda T, Kondo H, Kato K, Kishino T, Niikawa N, Wake N, Kato $\mathrm{H}$ : NECC1, a candidate choriocarcinoma suppressor gene that encodes a homeodomain consensus motif. Genomics 2003, 81(1):15-25.

12. Asanoma K, Kato H, Inoue T, Matsuda T, Wake N: Analysis of a candidate gene associated with growth suppression of choriocarcinoma and differentiation of trophoblasts. J Reprod Med 2004, 49(8):617-626.

13. Chen Y, Petersen S, Pacyna-Gengelbach M, Pietas A, Petersen I: Identification of a novel homeobox-containing gene, LAGY, which is downregulated in lung cancer. Oncology 2003, 64(4):450-458.

14. Chen Y, Pacyna-Gengelbach M, Deutschmann N, Niesporek S, Petersen I: Homeobox gene HOP has a potential tumor suppressive activity in human lung cancer. Int J Cancer 2007, 121(5):1021-1027.

15. Yamaguchi S, Asanoma K, Takao T, Kato K, Wake N: Homeobox gene HOPX is epigenetically silenced in human uterine endometrial cancer and suppresses estrogen-stimulated proliferation of cancer cells by inhibiting serum response factor. Int J Cancer 2009, 124(11):2577-2588.

16. Nishihira T, Hashimoto Y, Katayama M, Mori S, Kuroki T: Molecular and cellular features of esophageal cancer cells. J Cancer Res Clin Oncol 1993, 119(8):441-449.

17. Livak KJ, Schmittgen TD: Analysis of relative gene expression data using real-time quantitative PCR and the 2(-Delta Delta $C(T)$ ) Method. Methods 2001, 25(4):402-408.

18. Waraya M, Yamashita K, Katagiri H, Ishii K, Takahashi Y, Furuta K, Watanabe M: Preoperative serum CA19-9 and dissected peripancreatic tissue margin as determiners of long-term survival in pancreatic cancer. Ann Surg Oncol 2009, 16(5):1231-1240.

19. Dammann R, Schagdarsurengin U, Liu L, Otto N, Gimm O, Dralle H, Boehm BO, Pfeifer GP, Hoang-Vu C: Frequent RASSF1A promoter hypermethylation and $\mathrm{K}$-ras mutations in pancreatic carcinoma. Oncogene 2003, 22(24):3806-3812.

20. Pour PM, Pandey KK, Batra SK: What is the origin of pancreatic adenocarcinoma? Mol Cancer 2003, 2:13. 
21. Hennig R, Ding $X Z$, Adrian TE: On the role of the islets of Langerhans in pancreatic cancer. Histol Histopathol 2004, 19(3):999-1011.

22. Pour PM, Weide L, Liu G, Kazakoff K, Scheetz M, Toshkov I, Ikematsu Y, Fienhold MA, Sanger W: Experimental evidence for the origin of ductaltype adenocarcinoma from the islets of Langerhans. Am J Pathol 1997, 150(3):2167-2180.

23. Schmied BM, Ulrich AB, Matsuzaki H, Li C, Friess H, Bochler MW, AndronSandberg A, Adrian TE, Pour PM: Alteration of the Langerhans islets in pancreatic cancer patients. Int J Pancreatol 2000, 28(3):187-197.

24. Schmied BM, Ulrich AB, Matsuzaki H, Li C, Pour PM: In vitro pancreatic carcinogenesis. Ann Oncol 1999, 10(4):41-45.

25. El-Ghamari M, Bergmann F, Schmied BM, Weitz J, Ulrich A: Islet cells contribute to pancreatic carcinogenesis in an animal model. Pancreas 2011, 40(2):242-246.

26. Takahashi M, Furihata M, Akimitsu N, Watanabe M, Kaul S, Yumoto N, Okada $\mathrm{T}$ : A highly bone marrow metastatic murine breast cancer model established through in vivo selection exhibits enhanced anchorageindependent growth and cell migration mediated by ICAM-1. Clin Exp Metastasis 2008, 25(5):517-529.

27. Katoh H, Yamashita K, Waraya M, Margalit O, Ooki A, Tamaki H, Sakagami H, Kokubo K, Sidransky D, Watanabe M: Epigenetic silencing of HOPX promotes cancer progression in colorectal cancer. Neoplasia 2012, 14(7):559-571.

28. Kook H, Lepore JJ, Gitler AD, Lu MM, Wing-Man Yung W, Mackay J, Zhou R, Ferrari V, Gruber P, Epstein JA: Cardiac hypertrophy and histone deacetylase-dependent transcriptional repression mediated by the atypical homeodomain protein Hop. J Clin Invest 2003, 112(6):863-871.

29. Yin Z, Gonzales L, Kolla V, Rath N, Zhang Y, Lu MM, Kimura S, Ballard PL, Beers MF, Epstein JA, et al: Hop functions downstream of Nkx2.1 and GATA6 to mediate HDAC-dependent negative regulation of pulmonary gene expression. Am J Physiol Lung Cell Mol Physiol 2006, 291(2):L191-L199.

30. Kee HJ, Kim JR, Nam KI, Park HY, Shin S, Kim JC, Shimono Y, Takahashi $\mathrm{M}$, Jeong $\mathrm{MH}$, Kim $\mathrm{N}$, et al: Enhancer of polycomb1, a novel homeodomain only protein-binding partner, induces skeletal muscle differentiation. J Biol Chem 2007, 282(10):7700-7709.

31. Attwooll C, Oddi S, Cartwright P, Prosperini E, Agger K, Steensgaard P, Wagener C, Sardet C, Moroni MC, Helin K: A novel repressive E2F6 complex containing the polycomb group protein, $\mathrm{EPC1}$, that interacts with $\mathrm{EZH} 2$ in a proliferation-specific manner. J Biol Chem 2005, 280(2):1199-1208.

32. Aoto T, Saitoh N, Sakamoto Y, Watanabe S, Nakao M: Polycomb group protein-associated chromatin is reproduced in post-mitotic G1 phase and is required for S phase progression. J Biol Chem 2008, 283(27):18905-18915.

doi:10.1186/1471-2407-12-397

Cite this article as: Waraya et al: Cancer specific promoter CpG Islands hypermethylation of HOP homeobox (HOPX) gene and its potential tumor suppressive role in pancreatic carcinogenesis. BMC Cancer 2012 12:397.

\section{Submit your next manuscript to BioMed Central and take full advantage of:}

- Convenient online submission

- Thorough peer review

- No space constraints or color figure charges

- Immediate publication on acceptance

- Inclusion in PubMed, CAS, Scopus and Google Scholar

- Research which is freely available for redistribution 